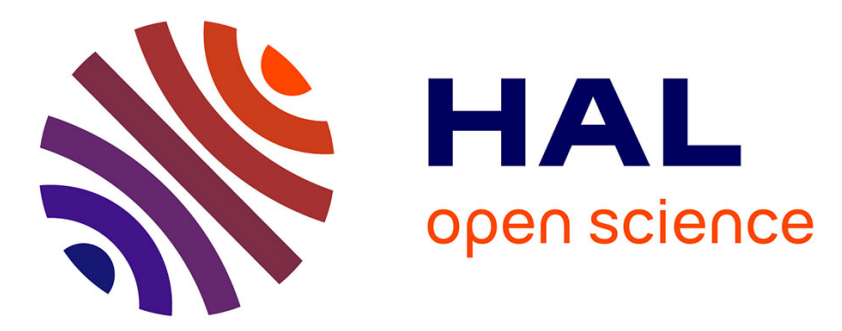

\title{
Pressure drop and average void fraction measurements for two-phase flow through highly permeable porous media
}

\author{
N. Chikhi, R. Clavier, J.-P. Laurent, F. Fichot, Michel Quintard
}

\section{To cite this version:}

N. Chikhi, R. Clavier, J.-P. Laurent, F. Fichot, Michel Quintard. Pressure drop and average void fraction measurements for two-phase flow through highly permeable porous media. Annals of Nuclear Energy, 2016, 94, pp.422 - 432. 10.1016/j.anucene.2016.04.007 . hal-02558462

\author{
HAL Id: hal-02558462 \\ https://hal.science/hal-02558462
}

Submitted on 7 Jan 2022

HAL is a multi-disciplinary open access archive for the deposit and dissemination of scientific research documents, whether they are published or not. The documents may come from teaching and research institutions in France or abroad, or from public or private research centers.
L'archive ouverte pluridisciplinaire HAL, est destinée au dépôt et à la diffusion de documents scientifiques de niveau recherche, publiés ou non, émanant des établissements d'enseignement et de recherche français ou étrangers, des laboratoires publics ou privés.

\section{(1) (1) $\$$}

Distributed under a Creative Commons Attribution - NonCommercial - NoDerivatives $\mid 4.0$ 


\section{OATAO}

\section{Open Archive TOULOUSE Archive Ouverte (OATAO)}

OATAO is an open access repository that collects the work of Toulouse researchers and makes it freely available over the web where possible.

This is an author-deposited version published in : http://oatao.univ-toulouse.fr/ Eprints ID : 15724

To link to this article : DOI:10.1016/j.anucene.2016.04.007 URL : http://dx.doi.org/10.1016/j.anucene.2016.04.007

To cite this version : Chikhi, Nourdine and Clavier, Rémi and Laurent, Jean-Paul and Fichot, Florian and Quintard, Michel Pressure drop and average void fraction measurements for two-phase flow through highly permeable porous media. (2016) Annals of Nuclear Energy, vol. 94. pp. 422 - 432. ISSN 0306-4549

Any correspondence concerning this service should be sent to the repository administrator: staff-oatao@,listes-diff.inp-toulouse.fr 


\title{
Pressure drop and average void fraction measurements for two-phase flow through highly permeable porous media
}

\author{
N. Chikhi ${ }^{\mathrm{a}, *}$, R. Clavier $^{\mathrm{a}}$, J.-P. Laurent ${ }^{\mathrm{b}, \mathrm{c}}$, F. Fichot $^{\mathrm{d}}$, M. Quintard $^{\mathrm{e}, \mathrm{f}}$ \\ a Institut de Radioprotection et de Sûreté Nucléaire (IRSN), PSN-RES/SEREX/LE2M, Cadarache bât. 327, 13115 St Paul-lez-Durance, France \\ ${ }^{\mathrm{b}}$ Univ. Grenoble Alpes, LTHE, F-38000 Grenoble, France \\ ${ }^{\mathrm{c}}$ CNRS, LTHE, F-38000 Grenoble, France \\ ${ }^{\mathrm{d}}$ Institut de Radioprotection et de Sûreté Nucléaire (IRSN), PSN-RES/SAG/LEPC, Cadarache bât. 700, 13115 St Paul-lez-Durance, France \\ e Université de Toulouse, INPT, UPS, Institut de Mécanique des Fluides de Toulouse (IMFT), Allée Camille Soula, F-31400 Toulouse, France \\ ${ }^{\mathrm{f}}$ CNRS, IMFT, F-31400 Toulouse, France
}

Keywords:

Debris bed

Pressure drop

Void fraction

Interfacial drag

\begin{abstract}
A B S T R A C T
The modeling of pressure drop for two-phase flows through porous media is a key point to assess the coolability of debris beds resulting from nuclear severe accidents. Models involve several parameters which are non-linear functions of the void fraction, e.g. relative permeabilities. Their identification requires that experimental data include the measurement of void fraction. This paper presents a new technique developed to reach this objective. The method is based on the use of a capacitance probe and has been validated by comparison with a weighing method. The validation has shown that the accuracy is better than $10 \%$. The measurement device has been implemented in the CALIDE facility, at IRSN, which has been designed to perform air-water flow through debris bed. Tests have been carried out with beds made of single size $4 \mathrm{~mm}$ and $8 \mathrm{~mm}$ beads. Measurements of pressure drop and average void fraction are reported in the paper, for air and water flow rates representative of flows that would result of either the reflooding of the damaged core or the cooling of corium debris in a stagnant pool of water. Finally, the pressure drop models used in severe accident simulation codes, based on generalizations of the single-phase Ergun law, have been assessed against the new data. It has been observed that generalized Ergun laws including an interfacial drag term accurately predict the pressure drop and the void fraction for flows with a zero net water velocity.
\end{abstract}

\section{Introduction}

The understanding of two-phase flow through high permeability porous media is of interest in several applications such as chemical reactors, oil/gas production or soil physics. In the field of nuclear safety analysis, the study of such flows has become of great importance after the TMI-2 accident (1979), where the injection of water on hot debris bed have stopped the progression of melting and led to keep the corium inside the reactor vessel (Broughton et al., 1989). By now, the assessment of debris coolability remains an open question. To address it, there is a need for a reliable thermal-hydraulic model able to estimate the debris heat removal rate during quenching or dry-out.

Several experimental investigations have been carried out to help modeling. Dry-out experiments (Hardee and Nilson, 1977;

\footnotetext{
* Corresponding author.

E-mail address: nourdine.chikhi@irsn.fr (N. Chikhi).
}

Dhir and Catton, 1977; Lipinski, 1984; Decossin, 1999) and reflood tests (top flooding: (Cho et al., 1984; Ginsberg et al., 1982; Tutu et al., 1984a; Tung and Dhir, 1988); bottom flooding: (Hall and Hall, 1981; Tutu et al., 1984c; Tung and Dhir, 1986)) have been performed, providing global parameters: outlet steam flow rate, quench front velocity, etc. The instrumentation was scarce so that only 0D/1D models have been developed, based on the counter current flow limitation (CCFL) and on correlations for the friction laws (Lipinski, 1982; Reed, 1982; Hu and Theofanous, 1991; Tung and Dhir, 1988; Schulenberg and Müller, 1987). 2D/3D models, which provide detailed flow fields (Fichot et al., 2006; Burger et al., 2006), have been developed. However, due to the lack of accurate local measurements in debris beds, models could not be validated. It is worth noticing that new data are available on large scale reflood tests (Chikhi et al., 2015). Two kinds of closure laws are required in these models: friction laws and heat transfer laws.

Since the generalization of Darcy's law by Muskat (1937), pressure drop models for two-phase flow through porous media involves parameters non-linearly dependent on saturation. In the 
context of nuclear safety, it is generally assumed (Schmidt, 2004) that the pressure drop is a function of the superficial gas and liquid velocities and of the void fraction (or gas saturation), i.e., $\Delta P=f\left(V_{l}, V_{g}, \alpha\right)$. Therefore, the inclusion of void fraction measurements in experimental data would seem an obvious requirement. And yet, the only data available in this field come from the experiments of Tutu et al. (1984b) with a zero net water flow. Schmidt (2004) compared the friction laws with these experimental data and showed that the pressure drop models should include an explicit interfacial friction term. Tung and Dhir proposed a modification of their model to take into account this feature by introducing a flow regime map (Tung and Dhir, 1988). Nevertheless, due to the lack of experimental data, the flow regime map could not be validated.

The bibliography related to the transposition of air-water flow to steam-water flow through porous media is quite scarce in the nuclear field. By now, there is no definitive conclusion on in this subject. Some studies have been done in petroleum and geothermal engineering field and a large review of results on steam-water relative permeability (laminar regime) can be found in Counsil (1979): Corey's equations to characterize steam-water relative permeability (Corey, 1977), Chen's drainage relative permeability curves (Chen et al., 1978) and Horne's curves relative permeability curves (Horne and Ramey, 1978). Few attentions have been paid to steam-water relative passability (inertial regime). More recently, discrepancies between steam and nitrogen injection have been reported in Jabbour et al. (1996).

The aim of the present paper is to propose an original method to measure the void fraction for air-water flows through nuclear-like debris bed. The method is based on the use of capacitance probes, widely used in soil physics (Zakri et al., 1998). It is presented in detail in Section 3. The measurement set-up has been implemented in the CALIDE facility (Chikhi et al., 2013), which is an air-water loop designed to generate two-phase flows through porous media. The CALIDE facility and the test conditions (flow regime and debris bed characteristics) are presented in Section 2. The capacitance probe method has been validated by comparison with a weighing method (Section 3). Different kinds of particles have been used to make the porous beds: glass beads, ceramic prisms and ceramic cylinders. Finally, pressure drop measurements have been performed on beds made of single-size spherical particles. Two beds have been built with $4 \mathrm{~mm}$ and $8 \mathrm{~mm}$ diameter spheres. The pressure drop have been measured for several gas and liquid mass flow rates that are representative of severe accident conditions. Section 4 is devoted to the presentation of these original experimental data. In Section 5, the classical pressure drop models cited above (Lipinski, Reed, Hu and Theofeanous, Tung and Dhir, Schulenberger and Muller), which are implemented in severe accident codes, are assessed against the experimental results.

\section{Experimental set-up}

\subsection{The CALIDE loop}

The CALIDE facility is an air/water single- and two-phase flow loop designed for pressure drop vs flow rate measurements for flow through porous media (Clavier et al. (2015) and Fig. 1). The test section containing the bed is made of a Plexiglas pipe (500 $\mathrm{mm}$ high and $94 \mathrm{~mm}$ diameter) which allows flow visualization. Air is supplied from the bottom and flows up through the bed, while water can flood the bed either from the top or the bottom, providing either co-current or counter-current flows. A stainless steel wire mesh is placed at the bottom of the test section to support the bed. This wire mesh has a negligible impact on the total pressure drop measured across the test section.
The fluid flow rates are measured and controlled by five high precision Bronkhorst ${ }^{\circledR}$ flowmeters with specific measuring ranges (see Table 1). Six radial holes uniformly distributed along the test section allow pressure tapping at different levels inside, downstream and upstream the debris bed. Pressure drops are measured by two Rosemount- $3051^{\circledR}$ differential pressure sensors (see Table 2). A thermocouple records the temperature at the top of the test section. This measured temperature is used for fluid viscosity $\mu$ and density $\rho$ calculation using tabulated values (Lide, 1990). The density is calculated for the average pressure to account for the gas compressibility (see Clavier et al. (2015) for more details).

\subsection{Debris bed}

A comprehensive review of the geometrical characteristics of nuclear debris beds can be found in Chikhi et al. (2014). One of the main conclusions of this study was that the particle size ranges from 0.3 to $10 \mathrm{~mm}$. The porosity ranges from 0.35 to 0.55 . It was also shown that, as far as pressure drop estimation is concerned, a debris bed made of polydisperse and non-spherical particles can be represented by an equivalent bed made of single-sized spherical particles either in the study of quenching or dry-out situation.

To validate the void fraction measurement method, a bed made of particles with identical shapes has been used. Several shapes were tested: spheres (glass), prisms (ceramic) and cylinders (ceramic) (Fig. 2). Their geometrical characteristics are given in Table 3.

For the integral tests devoted to pressure drop measurements, two beds have been studied, made of $4 \mathrm{~mm}$ and $8 \mathrm{~mm}$ glass beads. The bed properties have been measured and are given in Table 4 .

Bed porosities have been measured as the pressure losses are very sensitive to this parameter. To determine the bed porosity, the test section was filled with water with a mass $m_{w}$. The porosity is deduced using the water density $\rho_{w}$ :

$\varepsilon=\frac{4 m_{w}}{\rho_{w} \pi D^{2} H}$

where $H$ is the test section height and $D$ the test section diameter.

According to the particle diameter and to the porosity, two other bed characteristics can be calculated, the permeability $K$ and the passability $\eta$ :

$$
\begin{aligned}
& K=\frac{\varepsilon^{3} d^{2}}{h_{K}(1-\varepsilon)^{2}}, \\
& \eta=\frac{\varepsilon^{3} d}{h_{\eta}(1-\varepsilon)},
\end{aligned}
$$

where $h_{K}=181$ and $h_{\eta}=1.63$ are two empirical constants, which have been determined by fitting Ergun's law (Ergun, 1952)

$$
-\frac{\partial P}{\partial z}+\rho g=\frac{\mu}{K} U+\frac{\rho}{\eta} U^{2}
$$

against experiments as presented in a previous paper (Clavier et al., 2015) in the case of one-phase flows through beds packed with single-sized beads.

\subsection{Flow regime and test conduct}

The water and air flow rates have been chosen to be representative of water and steam filtration velocities during the reflood of a damaged core. Considering a reflood at low pressure in a French 1300 MWe PWR, the reflood mass flow rate is equivalent to a filtration velocity ranging from $5 \mathrm{~mm} / \mathrm{s}$ to $32 \mathrm{~mm} / \mathrm{s}$. The steam 


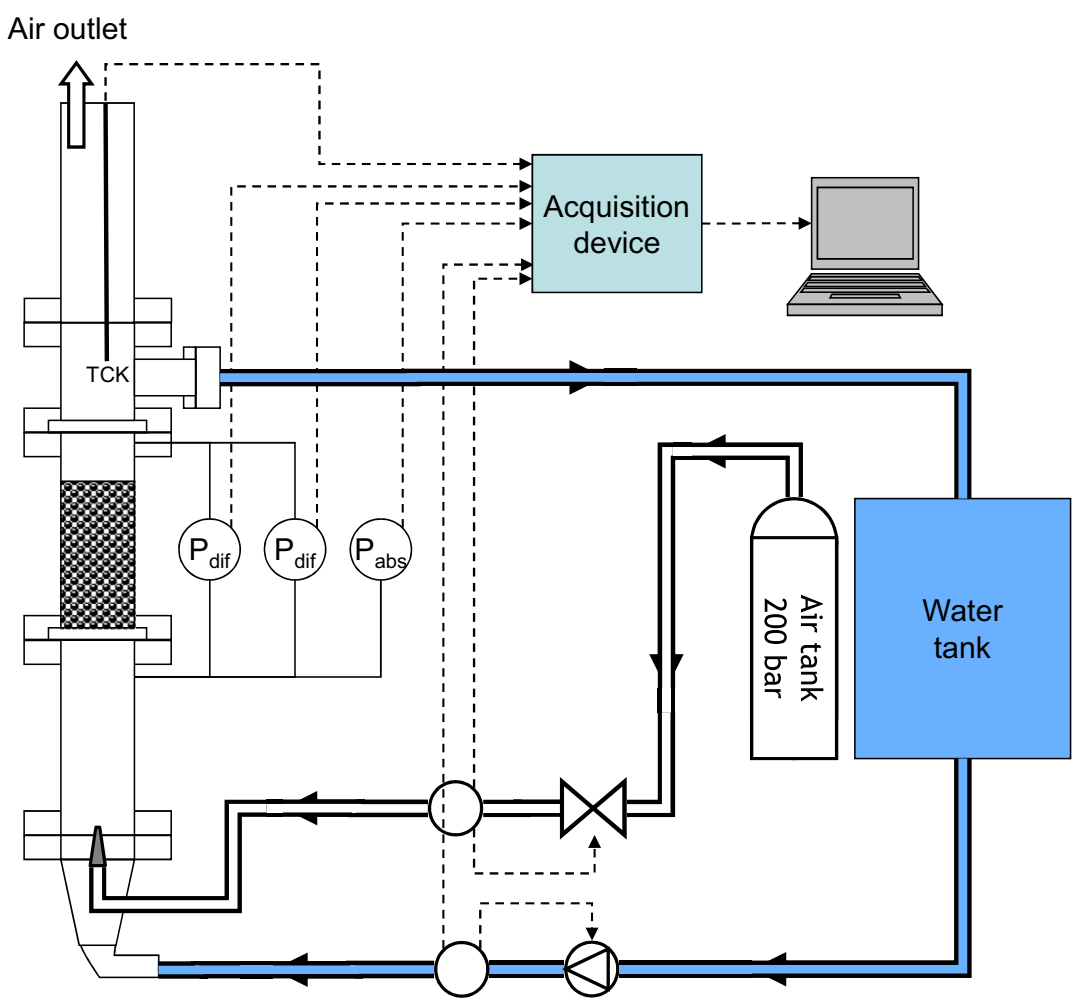

Fig. 1. The CALIDE facility.

Table 1

CALIDE flow meters.

\begin{tabular}{|c|c|c|c|}
\hline Flow meters & Type & Range & Accuracy \\
\hline BRONKHORST ${ }^{\circledR}$ F-201-CV & Air Flow & $0-10 \mathrm{NL} / \mathrm{min}$ & $0.5 \%$ Reading \\
\hline BRONKHORST ${ }^{\circledR}$ F-202-CV & Air Flow & $0-200 \mathrm{NL} / \mathrm{min}$ & $0.1 \%$ Reading \\
\hline BRONKHORST $^{\circledR}$ F-203-CV & Air Flow & $0-1000 \mathrm{NL} / \mathrm{min}$ & $0.1 \%$ Reading \\
\hline BRONKHORST ${ }^{\circledR}$ Cori-Flow M14 & Water Flow & $0-30 \mathrm{~kg} / \mathrm{h}$ & $0.2 \%$ Reading \\
\hline BRONKHORST $^{\circledR}$ Cori-Flow M15 & Water Flow & $0-600 \mathrm{~kg} / \mathrm{h}$ & $0.2 \%$ Reading \\
\hline
\end{tabular}

Table 2

CALIDE pressure sensors.

\begin{tabular}{|c|c|c|c|c|}
\hline Pressure sensors & Type & Range & Max. range (MR) & Accuracy \\
\hline ROSEMOUNT $^{\circledR} 3051$ & Differential & $-7 ;+7 \mathrm{mbar}$ & 14.19 mbar & $0.045 \% \mathrm{MR}$ \\
\hline ROSEMOUNT $^{\circledR} 3051$ & Differential & $-10 ;+200 \mathrm{mbar}$ & $1246 \mathrm{mbar}$ & $0.04 \%$ Reading $+0.023 \% \mathrm{MR}$ \\
\hline ROSEMOUNT $^{\circledR} 3051$ & Absolute & $0 ; 2$ bar & 55.2 bar & $0.025 \%$ Range \\
\hline
\end{tabular}

flow rate can be deduced from debris bed reflood experiments. According to PRELUDE tests (Repetto et al., 2013), the steam filtration velocities ranges from $1 \mathrm{~m} / \mathrm{s}$ to $7 \mathrm{~m} / \mathrm{s}$.

Two-phase flows have been generated into the two beds presented in the previous paragraph and in Table 4, and pressure drop measurements have been performed with the following conduct. The water mass flow rate was increased step by step for a given air mass flow rate. Each step had a duration of more than 180 s so that it can be assumed that the flow was stationary. This was confirmed by visual observations and stationarity of all probe measurements. The main parameters necessary for modeling have been measured: the pressure drop $\Delta P$, the filtration velocities $U_{l}$ and $U_{g}$, and the void fraction $\alpha$.

The test was also divided into four phases (see Fig. 3):
- low water and air flow rate: $\dot{m}_{l}=0 \rightarrow 30 \mathrm{~kg} / \mathrm{h}, \dot{m}_{g}=0 \rightarrow 10 \mathrm{NL} /$ min,

- high water flow rate, low air flow rate: $\dot{m}_{l}=0 \rightarrow 600 \mathrm{~kg} / \mathrm{h}$, $\dot{m}_{g}=0 \rightarrow 10 \mathrm{NL} / \mathrm{min}$,

- low water flow rate, high air flow rate: $\dot{m}_{l}=0 \rightarrow 30 \mathrm{~kg} / \mathrm{h}$, $\dot{m}_{g}=0 \rightarrow 200 \mathrm{NL} / \mathrm{min}$,

- high water and air flow rate: $\dot{m}_{l}=0 \rightarrow 600 \mathrm{~kg} / \mathrm{h}$, $\dot{m}_{g}=0 \rightarrow 200 \mathrm{NL} / \mathrm{min}$,

where $\dot{m}_{l}$ and $\dot{m}_{g}$ are respectively the liquid and gas mass flow rate. Thus, the CALIDE flowmeters have a range of filtration velocity from 0 to $24 \mathrm{~mm} / \mathrm{s} \equiv 600 \mathrm{~kg} / \mathrm{h}$ for water and from 0 to $0.5 \mathrm{~m} /$ $\mathrm{s} \equiv 200 \mathrm{NL} / \mathrm{min}$ for air. The maximum air flow rate had to be restricted to prevent fluidization of the bed. 

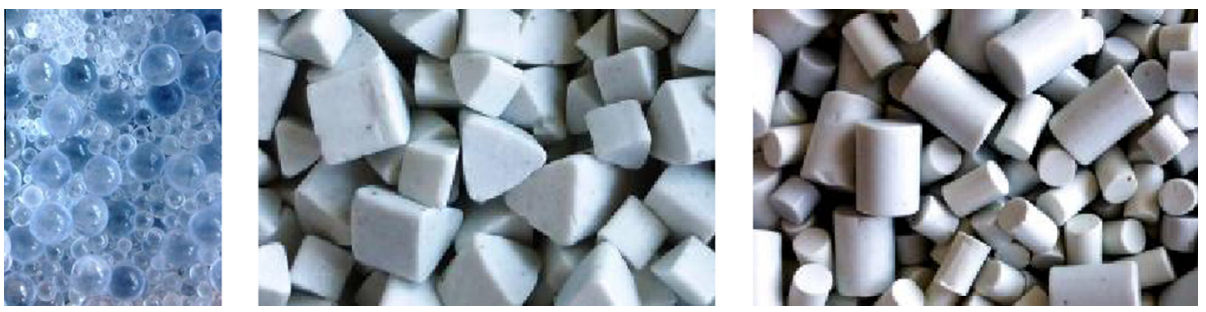

Fig. 2. Particles used to validate the void fraction measurement.

Table 3

Bed properties - validation.

\begin{tabular}{|c|c|c|c|c|c|}
\hline Bed name & Material & Diameter/side (mm) & Height $(\mathrm{mm})$ & Density $\left(\mathrm{kg} /{ }^{3}\right)$ & Porosity \\
\hline B3 - 1 & Glass spheres & $2.940 \pm 0.044$ & - & $2560 \pm 7.4$ & 0.380 \\
\hline B3 -2 & Glass spheres & $2.940 \pm 0.044$ & - & $2560 \pm 7.4$ & 0.399 \\
\hline B4 - 1 & Glass spheres & $4.058 \pm 0.031$ & - & $2560 \pm 7.4$ & 0.378 \\
\hline B4 - 2 & Glass spheres & $4.058 \pm 0.031$ & - & $2560 \pm 7.4$ & 0.379 \\
\hline B8 - 1 & Glass spheres & $7.877 \pm 0.116$ & - & $2560 \pm 7.4$ & 0.391 \\
\hline B8 - 2 & Glass spheres & $7.877 \pm 0.116$ & - & $2568 \pm 7.4$ & 0.391 \\
\hline $\mathrm{C} 5 * 5$ & Ceramic cylinder & $5.13 \pm 0.08$ & $4.53 \pm 0.23$ & $2572 \pm 7.4$ & 0.331 \\
\hline $\mathrm{C} 8 * 12-1$ & Ceramic cylinder & $7.99 \pm 0.10$ & $11.16 \pm 0.48$ & $2568 \pm 7.4$ & 0.357 \\
\hline $\mathrm{C} 8 * 12-2$ & Ceramic cylinder & $7.99 \pm 0.10$ & $11.16 \pm 0.48$ & $2568 \pm 7.4$ & 0.357 \\
\hline $\mathrm{P} 4 * 4$ & Ceramic prism & $4.15 \pm 0.11$ & $3.84 \pm 0.13$ & $2568 \pm 7.4$ & 0.331 \\
\hline
\end{tabular}

Several definitions of Reynolds numbers exist to characterize the flow regime in porous media (Kaviany, 1995). Here, the following expression is used as it suits well the granular medium:

$R e=\frac{d U \rho}{\mu(1-\varepsilon)}$,

where $d$ is the average particle size, $U$ is the filtration velocity, $\mu$ is the fluid viscosity. It gives $0<R e_{l}<300$ and $0<R e_{g}<500$.

\section{Void fraction measurement for two-phase flow through porous media}

Considering two-phase flows through porous media, the void fraction $\alpha$ is defined as the ratio between the volume occupied by the gas and the whole volume accessible to the fluid. It is related to the liquid "saturation", as commonly used in porous media physics, by the relation $s=1-\alpha$. Generally, the void fraction measurement in a porous medium is indirect, taking advantage of the differences of physical properties in each phase (liquid, gas and solid). Several techniques have been developed. Tutu et al. (1984b) used a weighting method, which works with a zero net water flow only and is suited to the measurement of an average saturation. Radiation methods -infra-red (Berhold et al., 1994), X-ray (Geffen and Gladfelter, 1952), $\beta$-ray (Zirnig, 1978), $\gamma$-ray (Yano, 1984)- were also used. They often allow for the measurement of local saturation within the porous medium, but they require heavy facilities and safety procedures. By analogy, ultrasound wave methods have been employed (Bensler, 1990) as well as Nuclear Magnetic Resonance (Saraf and Fatt, 1967). In our study, a new technique based on the use of capacitance probes has been developed, and will be presented in this section. Note that it has been protected by a patent (FR1551375). Example of capacitance probe application can be found in Gardner et al. (1998), Council and Ramey (1979) and Chen et al. (1978).

\subsection{Capacitive probes and set-up}

The capacitance probe CS-616 by Campbell Scientific ${ }^{\circledR}$ has been implemented into the CALIDE facility to measure the void fraction. It consists in two metal rods $(L \approx 30 \mathrm{~cm})$ connected to a sensor head. The metal rods are inserted in the debris bed (see Fig. 4), forming an electrical capacitor $(C)$. This capacitor is part of a RLC circuit, the resistor $R$ and the inductor $L$ being contained in the head sensor. The head sensor also contains an electric oscillator which is able to adjust its frequency $f$ on the resonance frequency of the RLC circuit 'debris bed + rods + sensor head'. The sensor head is linked by a waterproof connexion to an oscilloscope, thus providing the frequency $f$. The frequency depends on the capacitance $C$, which is proportional to the dielectric permittivity of the medium in which the rods are inserted. The dielectric permittivity itself depends on the medium composition (air/water/glass balls) and therefore on the void fraction, as the bed is supposed to be fixed. It means that the void fraction can be deduced from the frequency measurement, if a relation between the dielectric permittivity and the void fraction can be determined.

\subsection{Effect of void fraction on permitivity: Lichtenecker modeling}

The Lichtenecker model (Lichtenecker, 1926) proposes a relation between the global relative dielectric permittivity $K$ of a mixture of $N$ phases and their relative dielectric permittivities and volume fractions $K_{i}$ and $\varepsilon_{i}$ :

$K^{a}=\sum_{i=1, N} \varepsilon_{i} K_{i}^{a}$.

Table 4

Bed properties - pressure drop measurement.

\begin{tabular}{|c|c|c|c|c|c|c|}
\hline$\overline{\text { Bed } n^{o}}$ & Glass spheres (mm) & Diameter $(\mathrm{mm})$ & Balls density $\left(\mathrm{kg} /{ }^{3}\right)$ & Porosity & Permeability $\left(\mathrm{m}^{2}\right)$ & Passability (m) \\
\hline$\overline{1}$ & 4 & $4.058 \pm 0.031$ & $2560 \pm 7.4$ & 0.375 & $1.21 \mathrm{E}-8$ & $2.09 \mathrm{E}-4$ \\
\hline 2 & 8 & $7.877 \pm 0.116$ & $2568 \pm 7.4$ & 0.386 & $5.37 \mathrm{E}-8$ & $4.60 \mathrm{E}-4$ \\
\hline
\end{tabular}




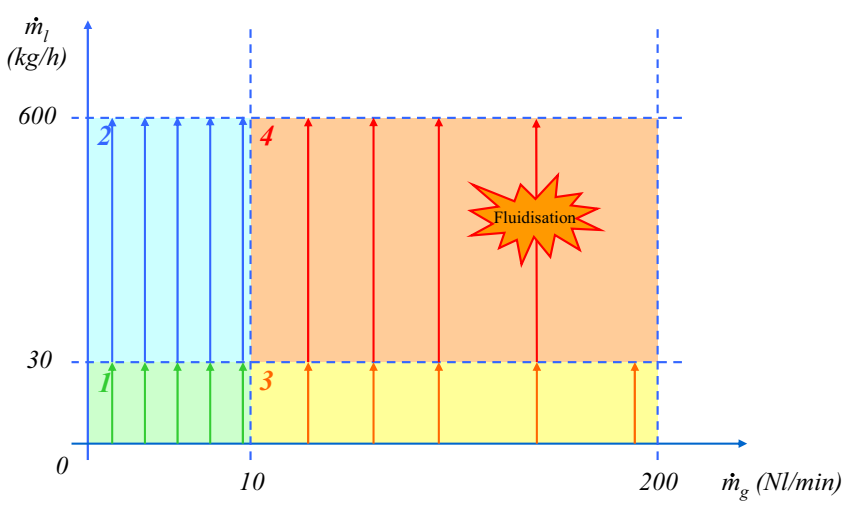

Fig. 3. Test phases.

The constant $a$ is depending on the geometry of the porous space. A theoretical justification for this mixing formula, which had hitherto been considered as empirical, has been proposed in Zakri et al. (1998). According to this model, the constant $a$ is such that $-1<a<1$ and, often $a \approx 0.5$ (Zakri, 1997). In our study, there are three phases in the test section: solid (glass beads), liquid (water) and gas (air). The solid matrix is fixed and, then, the solid fraction is constant and equal to $\varepsilon_{s}=1-\varepsilon$. The gas and liquid fractions are respectively equal to $\varepsilon_{g}=\varepsilon \alpha$ and $\varepsilon_{l}=\varepsilon(1-\alpha)$. Therefore, the Lichtenecker formula becomes:

$K^{a}=(1-\varepsilon) K_{s}^{a}+\varepsilon \alpha K_{g}^{a}+\varepsilon(1-\alpha) K_{l}^{a}$.

The relation between the permittivity $K$ and the frequency $f$ measured by the capacitance probe will now be derived. The capacitance of any capacitor is proportional to the dielectric permittivity:

$C=q_{\text {cap }} K$,

where $q_{\text {cap }}$ is a parameter depending on the geometrical configuration of the capacitor, which is constant in our study (two parallel cylindrical rods surrounded by an infinite medium). Furthermore, the frequency is linked to the capacitance $C$ and the inductance $L$ of the RLC circuit by the following relation:

$f=\frac{2 \pi}{\sqrt{L C}}$.

Therefore, the relation between the frequency and the void fraction can be written as:

$f^{-2 a}=\left(\frac{2 \pi}{\sqrt{q_{c a p} L}}\right)^{-2 a}\left(\left(\varepsilon K_{g}^{a}-\varepsilon K_{l}^{a}\right) \alpha+(1-\varepsilon) K_{s}^{a}+\varepsilon K_{l}^{a}\right)$.

This is a linear relation between $f^{-2 a}$ and $\alpha$. Therefore, it can be entirely determined with two calibration points. In our case, there are two situations where the value of the void fraction is obvious: first, when the bed is dry $\alpha=1$; second, when the bed is filled with water $\alpha=0$. As a consequence, the void fraction $\alpha$ can be deduced from the frequency $f$ by use of the following equation:

$\alpha=\frac{f^{-2 a}-f_{0}^{-2 a}}{f_{1}^{-2 a}-f_{0}^{-2 a}}$,

where $f_{0}=f(\alpha=0)$ and $f_{1}=f(\alpha=1)$.

\subsection{Validation}

Capacitance probes are currently used in soil physics, generally for water saturation measurements, but their applications are limited to quasi-static configurations, often with stratified phases. Their operation in two phase-flow situations is therefore original and it will now be demonstrated that this technique is indeed able to measure the void fraction for such application.

The capacitance probe has been set-up into the CALIDE facility to validate the void fraction measurement and to fit the parameter $a$ in the Lichtenecker formula. The void fraction is measured over a volume surrounding the probe (Fig. 4). The validation method consists in comparing the results obtained with the new method to the results that can be obtained with the weighing method used by Tutu et al. (1984b) and Schulenberg and Müller (1987).

To measure the void fraction with the weighing method, the test section is initially filled with water. The water level is fixed at the upper bound of the debris bed and a spillway is located, at this elevation, on the side of the test section in order to maintain the water level stable (Fig. 5a). Then, a constant air mass flow rate is supplied in the test section, from the bottom, which leads to an increase of the swollen water level and to a progressive evacuation of the water through the spillway (Fig. 5b). The swollen water level then decreases back to the upper bound of the debris bed, and a part of the water initially present in the test section is recovered in a container connected to the spillway (Fig. 5c). The volume of recovered water corresponds to the volume of air in the test section. It is deduced from its mass $m$. During this phase of the test, the frequency $f$ provided by the capacitance probe is measured by a numerical oscilloscope. Its value is fluctuating together with the two-phase air-water flow. The value is averaged over a time long enough such that the mean value remains constant. A part of the air volume stays under the grid which is supporting the debris bed. To determine this volume, the air flow rate is suddenly stopped (Fig. 5d). Then, there is a stratification with two layers - air and water. The grid is fine enough such that air cannot exit by the top through the bed. Finally, the void fraction in the bed can be deduced:

$\alpha=\frac{\frac{m}{\rho_{l}}-h S}{\varepsilon V_{b e d}}$,

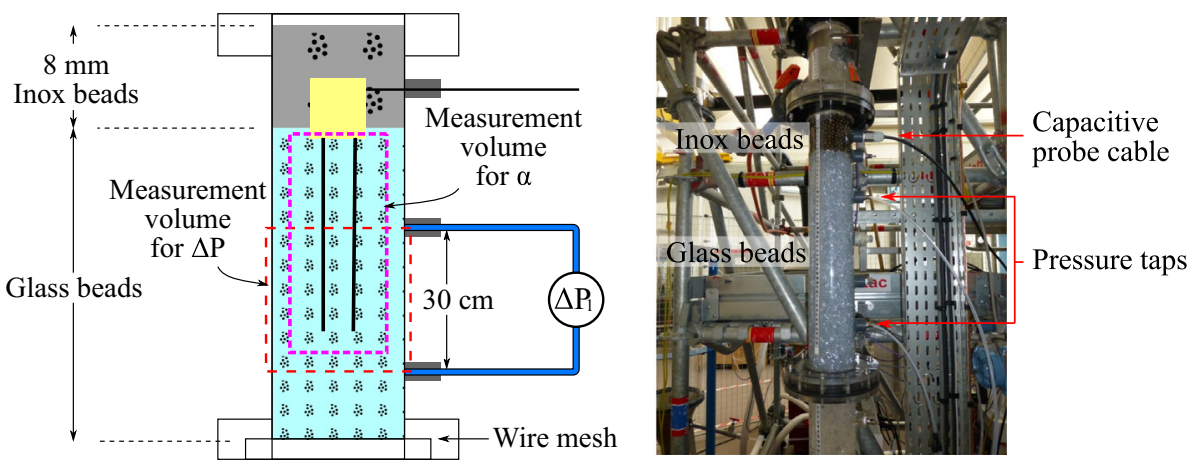

Fig. 4. Capacitive probe set-up. 

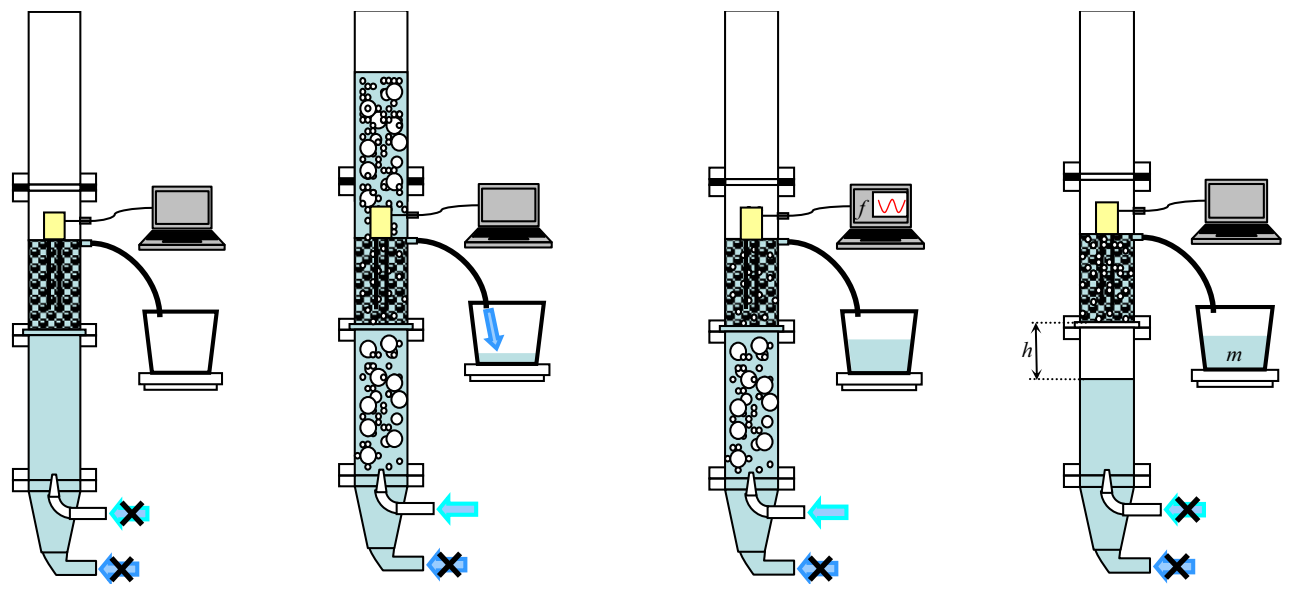

Fig. 5. Validation of the void fraction measurement using a weighing method.

where $h$ is the height of the air layer under the grid, $S$ is the area of the test section and $V_{\text {bed }}$ is the volume occupied by the bed in the test section. The uncertainty related to the weighing method has been estimated using the Guide to the Expression of Uncertainty in Measurement (GUM). This method is very accurate and reliable. The uncertainty remains lower than $1 \%$ for all the tests performed for the validation.

The validation includes series of tests on various debris bed with different sizes and shapes (Table 3). Several air mass flow rates were applied such that wide ranges of void fractions have been reached, from $10 \%$ to $80 \%$. In each test, the Lichtenecker parameter $a$ have been fitted. It has been concluded that the value $a=0.4$ allows very good agreement between the void fraction measurements by the capacitance probe and by the weighing method. The comparison between both methods is presented in Fig. 6. It demonstrates that the void fraction provided by the capacitance probe is reliable and precise, since the standard difference between the two methods is lower than $10 \%$. Note that the validation tests have been performed with a zero net water flow. Nevertheless, both phases -water and air- are locally moving due to flow fluctuation. As said before, the frequency $f$ is recorded and averaged over a long time. Finally, the mean value of frequency does not depend on the global air and water flow rate, but only the volumic fraction of each phase, as predicted by the Lichtenecker model. That is why the void fraction measurement can be used with a non-zero net water flow. It has been done and the results are presented in next section.

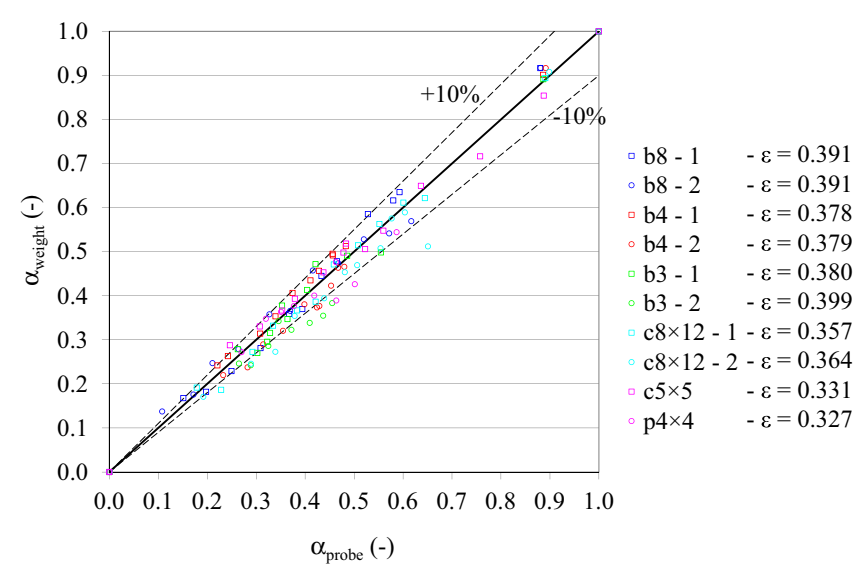

Fig. 6. Comparison between the void fraction measurements made with the capacitance probe and with the weighing method.

\section{Results}

Air-water flows have been generated through the prepared beds of glass beads for various mass flow rates, as listed in Table 4 . The pressure drop and the mean void fraction have been measured. The results are presented for each bed and compared to former tests.

\section{1. $4 \mathrm{~mm}$ beads debris bed}

Fig. 7 presents the void fraction measurements through $4 \mathrm{~mm}$ glass bead bed versus air and water filtration velocity. Each series of points corresponds to a constant liquid velocity. The void fraction ranges from $0 \%$ to $70 \%$. The results show that it depends mainly on the gas velocity. The void fraction increases together with the gas velocity, as expected. A correlation can be determined from these data with an accuracy of $10 \%$ :

$\alpha=0.11 \operatorname{Re}_{g}^{\frac{1}{3}}$,

where $R e_{g}$ is the Reynolds number for the gas phase:

$R e_{g}=\frac{d U_{g} \rho_{g}}{\mu_{g}(1-\varepsilon)}$.

The liquid velocity seems to have a negligible effect on the void fraction.

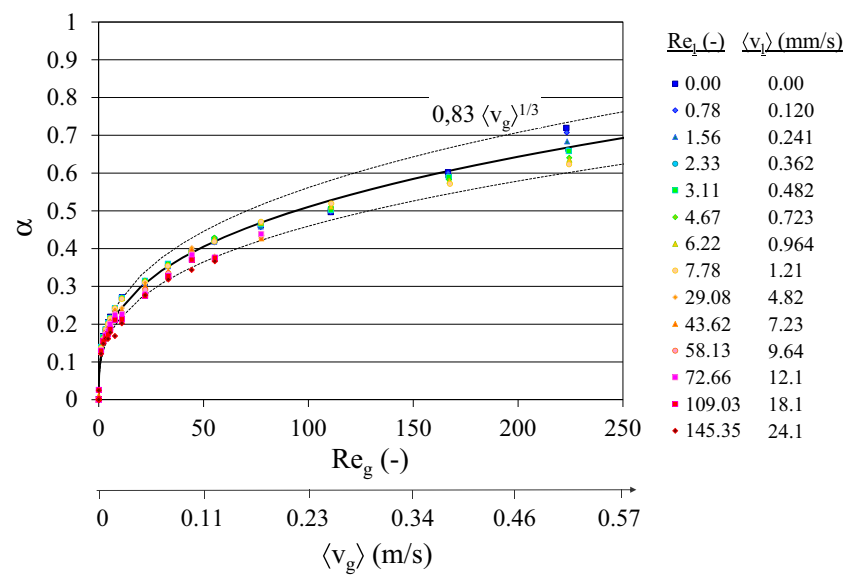

Fig. 7. Void fraction measurement for air-water flow through beds made with $4 \mathrm{~mm}$ glass beads as a function of air and water filtration velocities. 


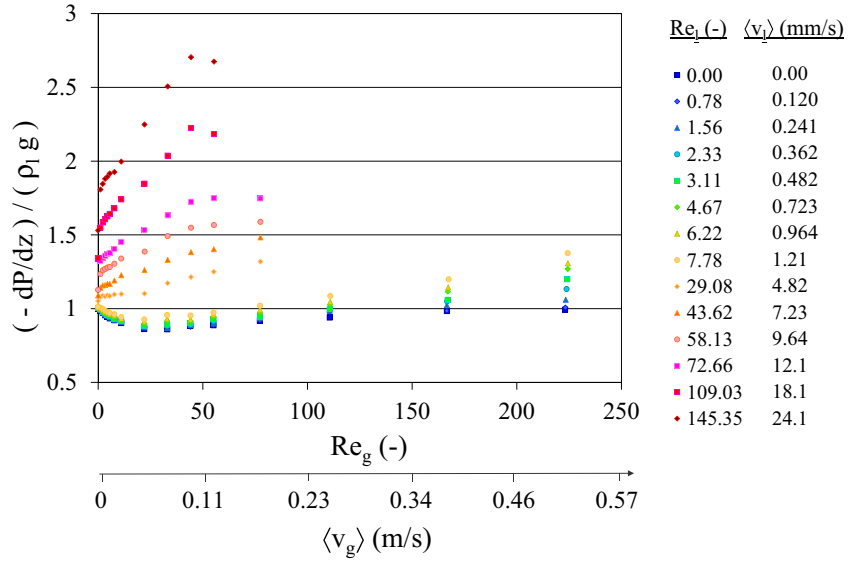

Fig. 8. Pressure drop measurement for air-water flow through beds made with $4 \mathrm{~mm}$ glass beads as a function of air and water filtration velocities.

Fig. 8 presents the pressure drop versus air and water filtration velocity. The pressure drop has been normalized by the hydrostatic pressure, such that it is equal to 1 when the water and air mass flow rates are null. As for the void fraction measurement, each series of points corresponds to a constant liquid velocity.

For a low water injection velocity, $V_{l}<4 \mathrm{~mm} / \mathrm{s}$, the pressure gradient first decreases below the hydrostatic gradient with increasing air flow rate, which is an indication of a significant force applied by the gas phase on the liquid phase, in the upward direction. After reaching a minimum, it increases for higher air flow rate. In the case $V_{l}=0 \mathrm{~mm} / \mathrm{s}$, it seems that the normalized pressure gradient tends to one, which is an indication that the effect of gas flow on the pressure drop becomes negligible at high gas flow rate. This is a striking observation which could be interpreted with the existence of at least two different flow configurations, one at low gas velocity and another one at high gas velocity. This seems to be confirmed in Fig. 7 where there is a change of slope for $V_{g}>0.3 \mathrm{~m} / \mathrm{s}$.

For a higher water velocity, $V_{l}>4 \mathrm{~mm} / \mathrm{s}$, the normalized pressure gradient increases continuously with the air velocity and it is always greater than one. This indicates that the flow configuration where the gas phase induces an upward force on the liquid phase becomes less significant when the water flow increases. It is an inertial effect.

\section{2. $8 \mathrm{~mm}$ balls debris bed}

Fig. 9 presents the void fraction measurement through $8 \mathrm{~mm}$ glass bead bed versus air and water filtration velocity. Each series

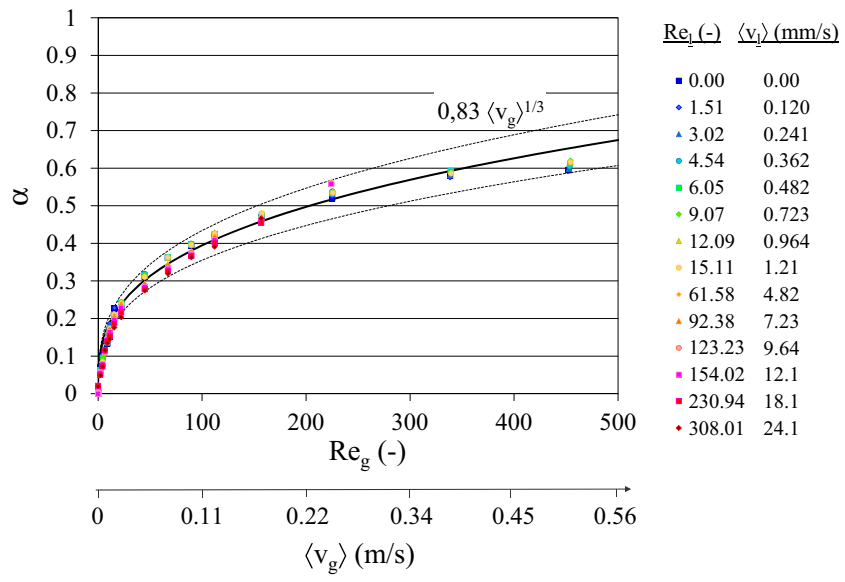

Fig. 9. Void fraction measurement for air-water flow through beds made with $8 \mathrm{~mm}$ glass beads as a function of air and water filtration velocities. of points corresponds to a constant liquid velocity. The void fraction ranges from $0 \%$ to $60 \%$. The results are close to those obtained with the bed made of $4 \mathrm{~mm}$ beads. The results show that it depends mainly on the gas velocity. The void fraction increases together with the gas velocity. A correlation can be determined from these data with an accuracy of $10 \%$ :

$\alpha=0.085 R_{g}^{\frac{1}{3}}$

The liquid velocity seems to have a negligible effect on the void fraction. It is worth noticing that the Reynolds number depends on the particle diameter. The ratio between both correlations (13) and (15) can be written as:

$\frac{0.11 \operatorname{Re}_{g}^{\frac{1}{3}}}{0.085 \operatorname{Re}_{g}^{\frac{1}{3}}}=\frac{0.11\left(d_{4}\left(1-\varepsilon_{8}\right)\right)^{\frac{1}{3}}}{0.085\left(d_{8}\left(1-\varepsilon_{4}\right)\right)^{\frac{1}{3}}}=1.03 \approx 1$.

Thus, the void fraction does not depend on the particle size and can be calculated by the following equation:

$\alpha=0.83 V_{g}^{\frac{1}{3}}$.

Fig. 10 presents the pressure drop depending on air and water filtration velocity. For low water injection velocities, $V_{l}<12 \mathrm{~mm} /$ $\mathrm{s}$, the pressure gradient decreases first below the hydrostatic gradient with increasing air flow rate. After reaching a minimum, it increases for higher air flow rates. When $V_{l}=0 \mathrm{~mm} / \mathrm{s}$, the normalized pressure gradient remains lower than 1 even for gas Reynolds number greater than 200 . This indicates that the flow configuration where the gas phase induces an upward force on the liquid phase is more significant for the $8 \mathrm{~mm}$ particles.

For higher water velocity, $V_{l}>12 \mathrm{~mm} / \mathrm{s}$, the pressure gradient increases continuously with the air velocity and it is always greater than 1 . As will be discussed later, these qualitative behaviors can be used to validate certain forms of the macroscale equations.

\subsection{Comparison with former Tutu experiment}

As said in the introduction, Tutu performed experiments to study the pressure drop for air-water flow through debris beds. These tests were carried out with a zero net water flow and provided void fraction measurements by use of a weighing method. Three particle diameters were used to build the debris bed: $3.18 \mathrm{~mm}, 6.35 \mathrm{~mm}$ and $12.7 \mathrm{~mm}$. These data are currently used in the framework of modeling (Schmidt, 2006).

The results of Tutu experiments are presented together with the results of the present work in Figs. 11 and 12.

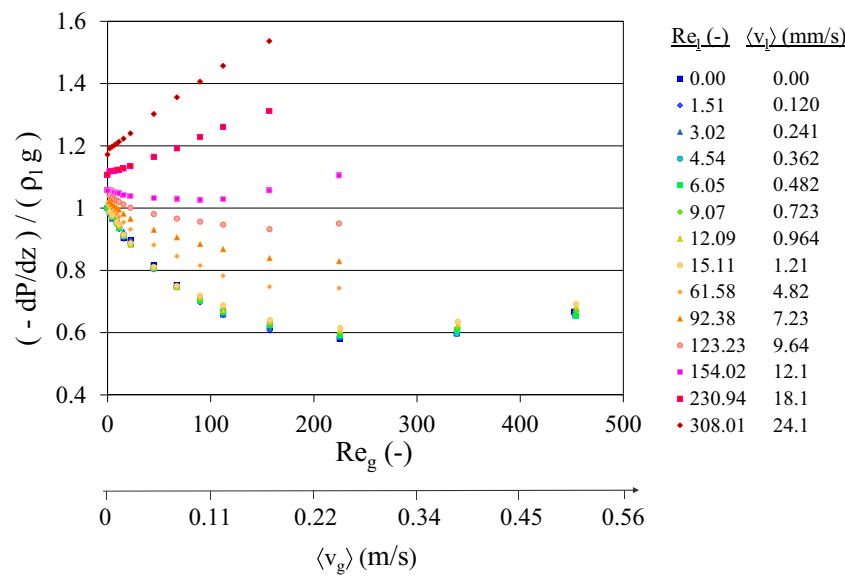

Fig. 10. Pressure drop measurement for air-water flow through beds made with $8 \mathrm{~mm}$ glass beads as a function of air and water filtration velocities. 


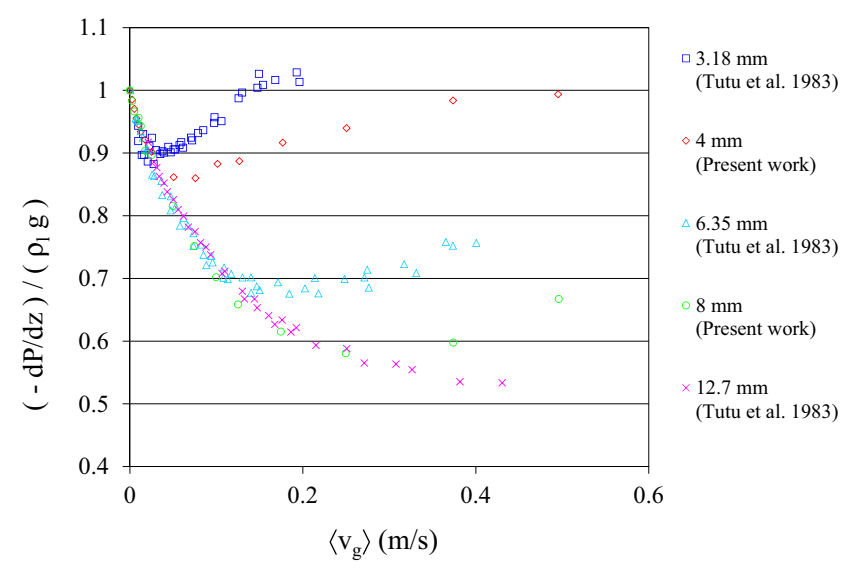

Fig. 11. Comparison of the results from CALIDE facility with former Tutu experiments: normalized pressure gradient vs air velocity.

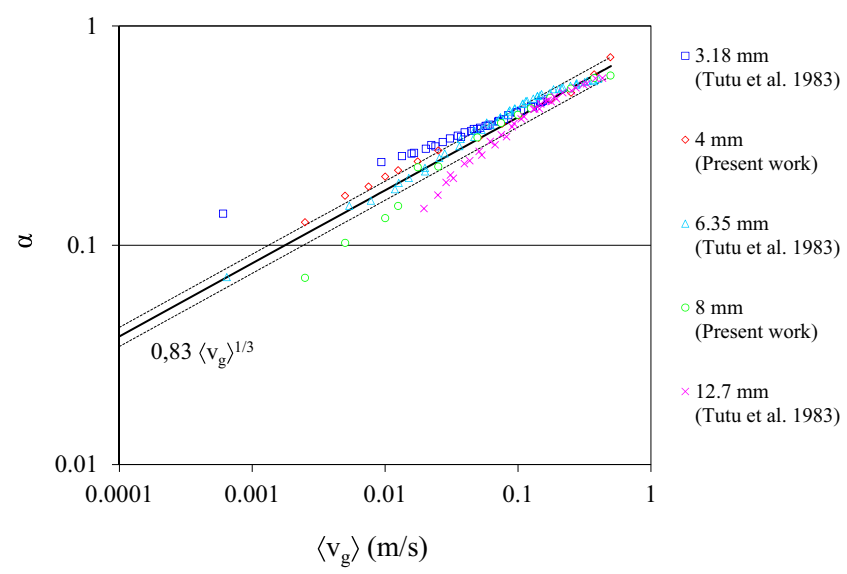

Fig. 12. Comparison of the results from CALIDE facility with former Tutu experiments: void fraction vs air velocity.

For low air velocity, the normalized pressure gradient decreases together with the air velocity with the same slope regardless of the particle diameter. However, the air velocity corresponding to the minimum value for the pressure gradient is increasing with the diameter.

Eq. (17) has been reported on Fig. 12. Its prediction of the void fraction is valid, with an accuracy of $\pm 10 \%$, for void fraction greater than 0.3 . This results is supported for all particle diameters from $3 \mathrm{~mm}$ to $12 \mathrm{~mm}$.

Generally speaking, the results obtained in the CALIDE facility using the capacitance probe to measure the void fraction are consistent with those of Tutu et al. (1984b). This confirms the quality and accuracy of the new data proposed in the paper. Therefore, the new data obtained with a non-zero water flow can be considered as reliable.

\section{Discussion}

To understand what is at stake when discussing the obtained phenomenological results, one needs to consider the type of macro-scale momentum equations proposed in the literature. The most widely used model corresponds to the generalized Darcy's law proposed by Muskat (1937). For the $l$-phase in 1D, we have

$-\frac{\partial P_{l}}{\partial z}-\rho_{l} g=\frac{\mu_{l}}{K K_{l}} U_{l}$, where $K_{l}$ stands for the relative permeability that is a non-linear function of $\alpha$. An obvious consequence of this model is that, if $U_{l}=0$, one has $\frac{\partial P_{l}}{\partial z}=-\rho_{l} g$, which is not consistent with our experimental findings. Indeed, this model is not entirely supported by mathematical upscaling techniques. Theoretical developments based on the assumption of quasi-steady and quasi-static flows and low Bond number for a Representative Elementary Volume lead to generalized Darcy's laws with additional crossterms accounting for the viscous interaction between the two phases (Whitaker, 1986). Inertia terms have been added under the form of Forchheimer terms, a popular form being the classical Ergun's law used in Chemical Engineering. It reads

$-\frac{\partial P_{l}}{\partial z}-\rho_{l} g=\frac{\mu_{l}}{K K_{l}} U_{l}+\frac{\rho_{l}}{\eta \eta_{l}} U_{l}^{2}$

for the $l$-phase, where $\eta$ is called the passability and $\eta_{l}$ the relative passability depending on $\alpha$. This form is not also entirely supported by upscaling techniques which again suggest the introduction of viscous and inertia cross terms in addition to the Forchheimer terms in Eq. (19) (Lasseux et al., 2008). This point is further discussed below.

Before proceeding to this analysis, one must remember that all the models presented above make assumptions of nearly quasisteady and quasi-static pore-scale flows. It is not proved that such assumptions are correct in the context of nuclear safety. Indeed, two-phase flow in highly permeable media are subject to complex, transient pore-scale mechanisms. Theoretical models for dynamic two-phase flows have been proposed in the literature (Kalaydjian, 1987; Quintard and Whitaker, 1990; Hassanizadeh and Gray, 1993; Hilfer, 1998; Panfilov and Panfilova, 2005,...). This problem to date is still a rather open research domain. In this study, we only consider the extensions of the generalized Darcy's law including cross-terms and inertia terms.

\subsection{Pressure drop model}

Several models were developed to describe the friction laws for two-phase flows through porous medium. The models used in severe accident codes are based on a generalization of Ergun law from single- to two-phase flows:

$-\frac{\partial P_{l}}{\partial z}-\rho_{l} g=\frac{\mu_{l}}{K K_{l}} U_{l}+\frac{\rho_{l}}{\eta \eta_{l}} U_{l}^{2}-\frac{F_{i}}{1-\alpha}$,

$-\frac{\partial P_{g}}{\partial z}-\rho_{g} g=\frac{\mu_{g}}{K K_{g}} U_{g}+\frac{\rho_{g}}{\eta \eta_{g}} U_{g}^{2}+\frac{F_{i}}{\alpha}$

As discussed before, they can be divided in two groups, whether they include (Tung and Dhir, 1988; Schulenberg and Müller, 1987) or not (Lipinski, 1982; Reed, 1982; Hu and Theofanous, 1991) a term to represent the interfacial drag $F_{i}$. It is important to note that, for stagnant water, i.e., zero net water flow, the models which do not include a term for interfacial drag give a normalized pressure gradient equal to 1 , whatever the gas velocity (see above discussion about Eq. (18)). For the first group, the correlations proposed for relative permeability and passability are summarized in Table 5.

Table 5

Pressure drop models.

\begin{tabular}{llllll}
\hline Model & $K_{g}$ & $\eta_{g}$ & $K_{l}$ & $\eta_{l}$ & $F_{i}$ \\
\hline Lipinski & $\alpha^{3}$ & $\alpha^{3}$ & $(1-\alpha)^{3}$ & $(1-\alpha)^{3}$ & 0 \\
Reed & $\alpha^{3}$ & $\alpha^{5}$ & $(1-\alpha)^{3}$ & $(1-\alpha)^{5}$ & 0 \\
Hu and Theofanous & $\alpha^{3}$ & $\alpha^{6}$ & $(1-\alpha)^{3}$ & $(1-\alpha)^{6}$ & 0
\end{tabular}


The Schulenberg and Muller model proposed the following expression of the interfacial drag:

$F_{i}=350(1-\alpha)^{7} \alpha \frac{\rho_{l} K}{\eta \sigma}\left(\rho_{l}-\rho_{g}\right) g\left(\frac{U_{g}}{\alpha}-\frac{U_{l}}{1-\alpha}\right)^{2}$

The expressions for permeability and passability in the liquid phase are assumed to be the same as those proposed by Reed. For the gas, it was proposed: $K_{g}=\alpha^{3}$ and

$\eta_{g}=0.1 \alpha^{4}$ if $0<\alpha<0.3$

$\eta_{g}=\alpha^{6}$ if $0.3<\alpha<1$

The model of Tung and Dhir is based on visual observations of air-water flow experiments. From that, they deduced flow patterns: bubbly, slug and annular flows, and intermediate mixed flowing regimes. For each regime, correlations were proposed. They are detailed in Tung and Dhir (1988).

\subsection{Assessment of model against experiment}

Comparisons were made between the above-mentioned models and the experimental results. In the models, the void fraction $\alpha$ is obtained by an implicit resolution of Eqs. (20) and (21). Four configurations have been investigated with:

- two water injection velocities: $V_{l}=0 \mathrm{~mm} / \mathrm{s}$ and $V_{l}=18 \mathrm{~mm} / \mathrm{s}$,

- two bead sizes: $4 \mathrm{~mm}$ and $8 \mathrm{~mm}$.

Figs. 13 and 14 present the experimental void fraction and pressure drop measurements as a function of the gas velocity together with the model predictions, for the case $V_{l}=0 \mathrm{~mm} / \mathrm{s}$.

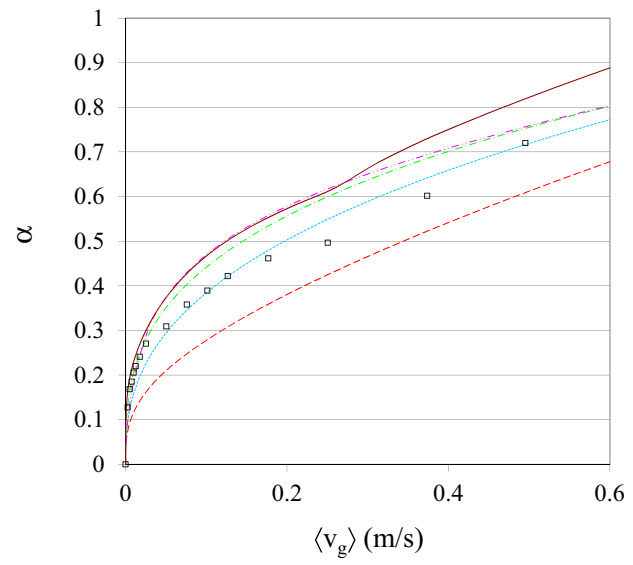

\section{$\square$ Exp \\ ---Lipinski \\ Reed}

Hu\&Theofanous

Schulenberg

- Tung\&Dhir

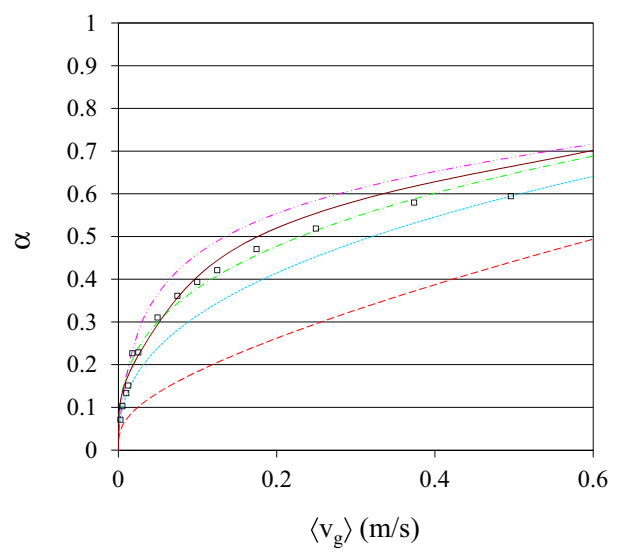

\section{- Exp}

---Lipinski

Reed

Hu\&Theofanous

-Schulenberg

- Tung\&Dhir

Fig. 13. Void fraction measurement for air-water flow through packed beds made with $4 \mathrm{~mm}$ (left) and $8 \mathrm{~mm}$ (right) glass beads vs models for $V_{l}=0 \mathrm{~mm} / \mathrm{s}$.
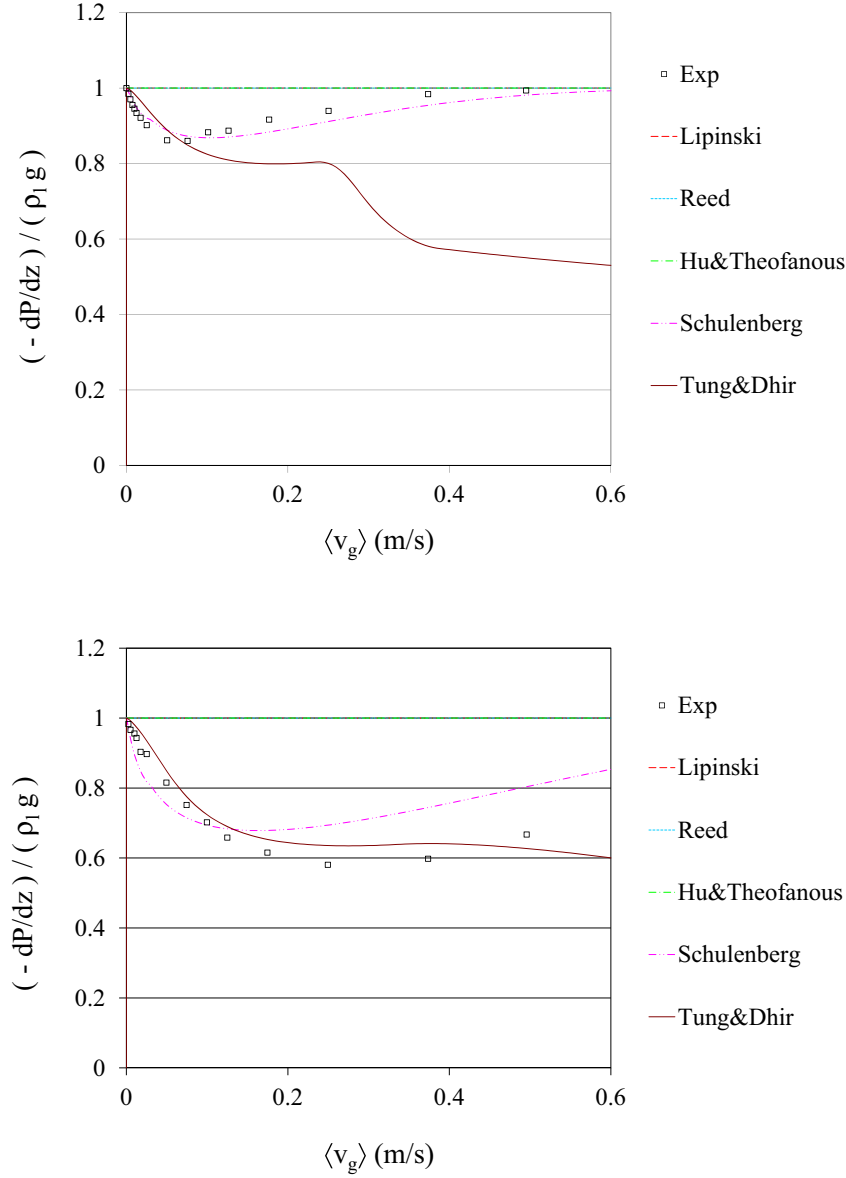

Fig. 14. Pressure drop measurement for air-water flow through packed beds made with $4 \mathrm{~mm}$ (left) and $8 \mathrm{~mm}$ (right) glass beads bed vs models for $V_{l}=0 \mathrm{~mm} / \mathrm{s}$.

Given the fact that a variation of $\alpha$ of about 0.1 gives rise to important variations of the relative permeability or passabilities, which are expressed by power laws, one may consider that there are significant differences between the estimations of the various models. Those of Reed, Lipinski and Hu et al. give better estimates for both particle sizes, still with differences of several per cent in void fraction value. In addition, the model of Tung and Dhir is the only one to catch the change of slope for the $4 \mathrm{~mm}$ balls, although it overestimates the void fraction by about 0.10 .

The first important observation about the normalized pressure drop is that it is lower than 1 when increasing the gas velocity. As discussed above, this is a behavior which is predicted by models including the drag between the liquid and the gas. Therefore, since this effect is not negligible, models which do not consider the interfacial drag must be discarded in most situations related to nuclear safety analysis. Models with interaction terms (Schulenberg and Müller, 1987; Tung and Dhir, 1988) feature a pressure gradient decrease with increasing gas velocity in qualitative agreement with the experimental data, but the model of Schulenberg and Muller is the only one to predict the increase for higher gas velocities and therefore the existence of a minimum.

Figs. 15 and 16 present the experimental results for void fraction and pressure drop measurements together with the model predictions for $V_{l}=18 \mathrm{~mm} / \mathrm{s}$.

The void fraction is far underestimated by the models of Lipinski and Reed. The models of Tung and Dhir, Schulenberg and Muller, Hu and Theofanous provide values in better agreement with the experimental data, still short of a very accurate prediction. 

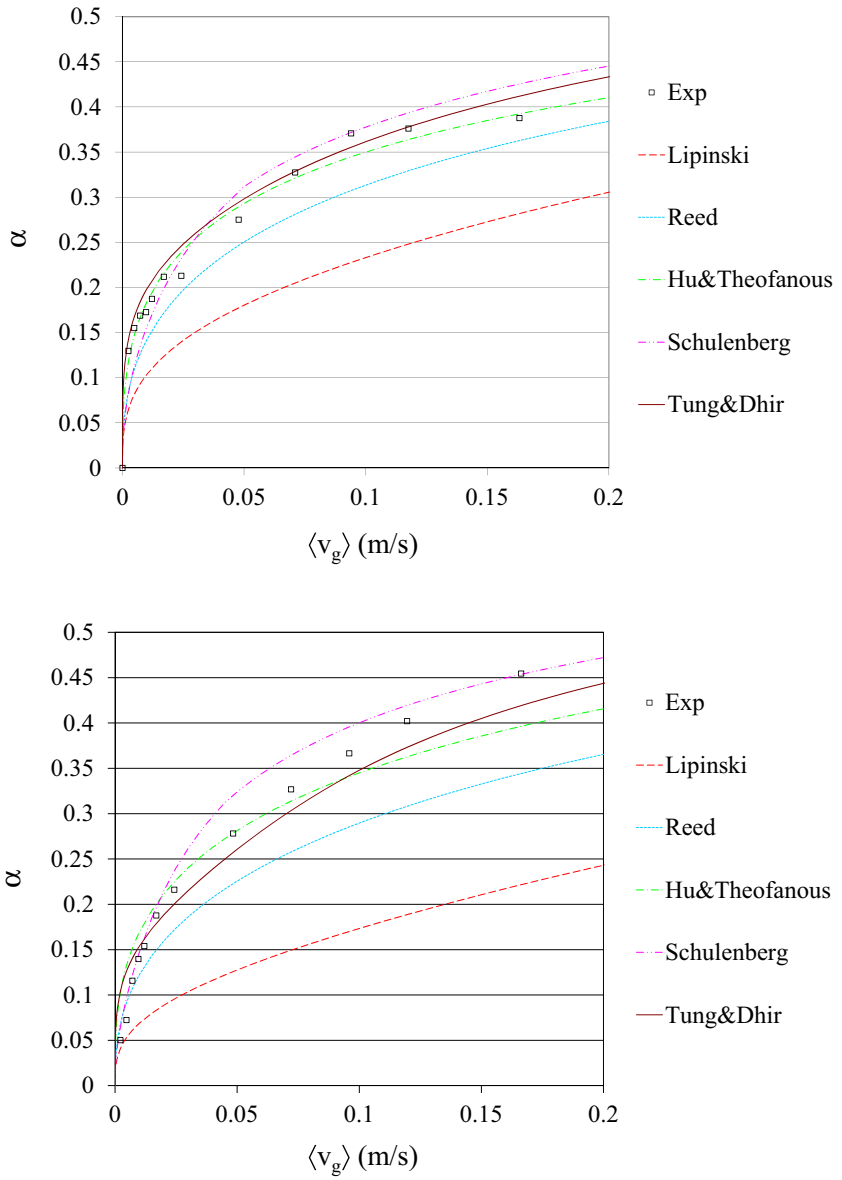

Fig. 15. Void fraction measurement for air-water flow through packed beds made with $4 \mathrm{~mm}$ (left) and $8 \mathrm{~mm}$ (right) glass beads vs models for $V_{l}=18 \mathrm{~mm} / \mathrm{s}$.

All models, except Lipinski's one, overestimate the pressure drop. The model of Tung and Dhir, and Lipinski give fair estimation of the pressure drop for the $8 \mathrm{~mm}$ beads. No model is able to propose a good estimation of the pressure drop for the $4 \mathrm{~mm}$ ball bed.

As a conclusion, none of the existing models is able to predict correctly the void fraction and the pressure gradient for the 4 cases selected from our data. This is not really surprising because those models were only validated with data obtained for the $V_{l}=0$. New correlations have to be proposed in order to cover the whole range of flow parameters and particle diameters which are expected in reactor situations. From the preliminary comparisons shown in this paper, it appears necessary to include some terms representing the interfacial drag or, at least, the effect of the gas velocity on the liquid phase pressure gradient, in addition to the standard relative permeability and passability terms. This is in accordance with theoretical suggestions based on upscaling techniques.

\section{Conclusions}

A new method was developed for measuring the void fraction for two-phase flows in beds of coarse particles. This technology, based on the use of a capacitance probe, was implemented in the CALIDE facility and validated by comparison to a weighing method. Integral tests have been performed subsequently on single-size debris beds made of $4 \mathrm{~mm}$ and $8 \mathrm{~mm}$ glass beads. Air-water flows were studied, for wide and representative ranges of air and water flow rates. The experimental campaign provided original data including air and water velocities, pressure drop and, for the first time, void fraction. The results were compared to former tests
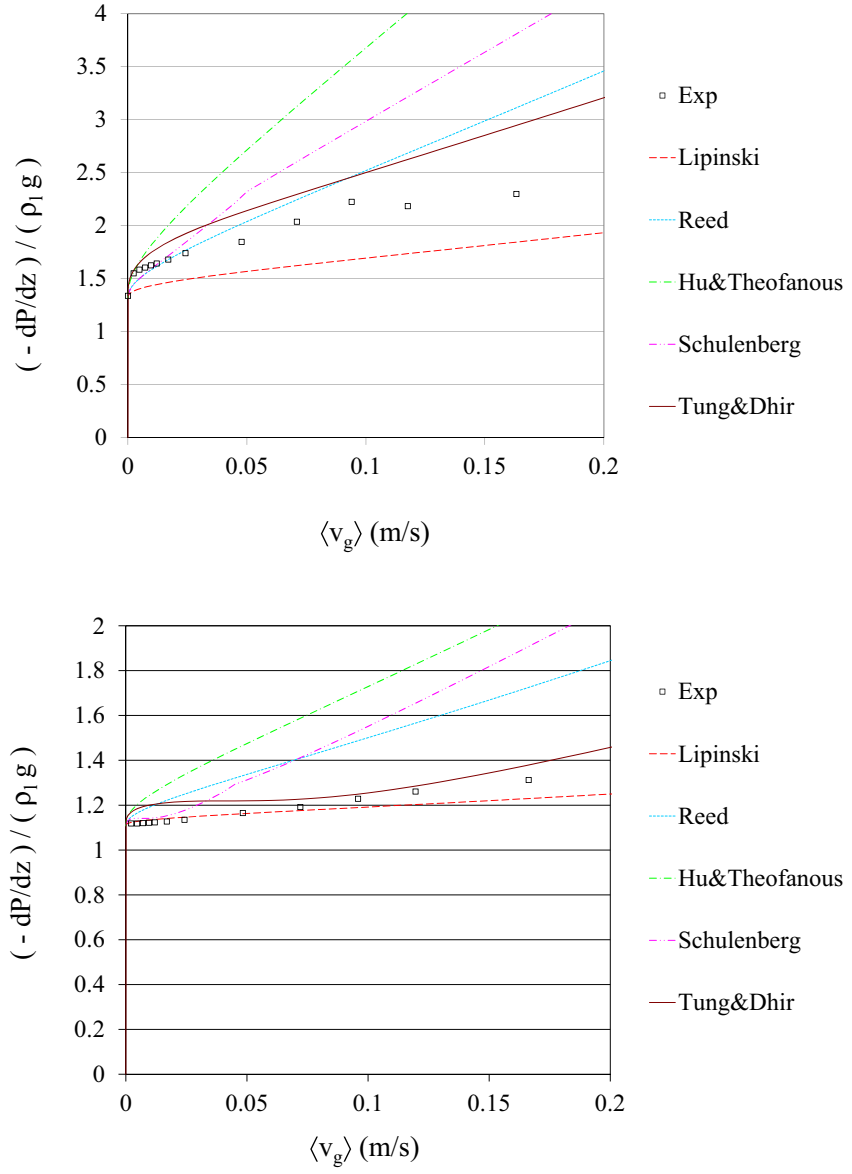

Fig. 16. Pressure drop measurement for air-water flow through packed beds made with $4 \mathrm{~mm}$ (left) and $8 \mathrm{~mm}$ (right) glass beads vs models for $V_{l}=18 \mathrm{~mm} / \mathrm{s}$.

performed with a zero net water flow rate, and showed a very good agreement and consistency. This gives confidence in the reliability of the data obtained for non zero water flow rates.

The data demonstrate the strong impact of interfacial friction phenomena and give indications on possible differences of flow configurations, depending on the gas velocity. Finally, the classical pressure drop models implemented in severe accident codes have been assessed against the new data. Generally speaking, the usual generalized of Ergun laws are not appropriate to model two-phase flows across coarse debris beds because they cannot reproduce the decrease of pressure drop at low gas velocity. The introduction of an interfacial drag term provides a significant improvement in the modeling of configurations with a zero net water flow, but the new obtained data showed that it is not sufficient to consider flows with $V l>0$. This is a clear indication that the phenomenology of friction between phases is not enough understood and requires further investigations. The new set of data presented in this paper may help deriving more relevant and accurate models.

\section{Acknowledgement}

The authors thanks EDF for funding part of this work.

\section{References}

Bensler, H., 1990. Détermination de l'aire interfaciale, du taux de vide et du diamètre moyen de Sauter dans un écoulement à bulles à partir de l'atténuation d'un faisceau d'ultrasons (Ph.D. thesis). Institut National Polytechnique de Grenoble. 
Berhold, J., Reed, S., Nash, C., 1994. Fibre optic sensor system for void fraction bermeasurement in aqueous two-phase fluids. Flow Meas. Instrum. 5, 3-13.

Broughton, J., Kuan, P., Petti, D., Tolman, E., 1989. A scenario of the three mile island unit 2 accident. Nucl. Technol. 87, 34-53.

Burger, M., Buck, M., Schmidt, W., Widmann, W., 2006. Validation and application of the WABE code: investigations of constitutive laws and 2D effects on debris coolability. Nucl. Eng. Des. 236, 2164-2188.

Chen, H.K., Counsil, J.R., Ramey, H., 1978. Experimental steam-water permeability curves. GRC Trans. 2, 102-104.

Chikhi, N., Coindreau, O., Li, L., Ma, W., Taivassalo, V., Takasuo, E., Leininger, S., Kulenovic, R., Laurien, E., 2014. Evaluation of an effective diameter to study quenching and dry-out of complex debris bed. Ann. Nucl. Energy 74, 24-41.

Chikhi, N., Garcin, T., Foubert, F., March, P., Fichot, F., 2015. First experimental results of large scale debris bed reflood tests in the PEARL tests. In: 16th International Topic Conference on Nuclear Reactor Themalhydraulic (NURETH16), Chicago, USA.

Chikhi, N., Lenoir, B., Garcin, T., 2013. Reflooding a damaged core: characterization of debris beds. In: 15th International Topic Conference on Nuclear Reactor Themalhydraulic (NURETH-15), Pisa, Italia.

Cho, D., Armstrong, D., Chan, S., 1984. On the pattern of water penetration into a hot particle bed. Nucl. Technol. 65, 23-31.

Clavier, R., Chikhi, N., Fichot, F., Quintard, M., 2015. Experimental investigation on single-phase pressure losses in nuclear debris beds: identification of flow regimes and effective diameter. Nucl. Eng. Des. 292, 222-236.

Corey, A., 1977. Mechanics of Heterogeneous Fluids in Porous Media. Water Resources Publications, Fort Collins, Colorado.

Council, J.R., Ramey, H., 1979. Drainage relative permeabilities obtained from steam-water boiling flow and external gas drive experiments. GRC Trans. 3, 141-143.

Counsil, J., 1979. Steam-water relative permeability (Ph.D. thesis). Stanford University.

Decossin, E., 1999. Numerical investigations on particulate debris bed coolability: critical analysis of the silfide experimental project. In: Ninth International Topical Meeting on Nuclear Reactor Thermal Hydraulics (NURETH-9), San Francisco, California.

Dhir, V., Catton, I., 1977. Study of dryout heatfluxes in beds of inductively heated particles. Technical Report NUREG CR-0262 Technical report.

Ergun, S., 1952. Fluid flow through packed columns. Chem. Eng. Prog. 48, 89-94.

Fichot, F., Duval, F., Trégourès, N., Béchaud, C., Quintard, M., 2006. The impact of thermal non equilibrium and large scale 2D/3D effects on debris bed reflooding and coolability. Nucl. Eng. Des. 236, 2144-2163.

Gardner, C., Dean, T., Cooper, J., 1998. Soil water content measurement with a highfrequency capacitance sensor. J. Agric. Eng. Res. 71, 395-403.

Geffen, T., Gladfelter, R., 1952. A note on the x-ray absorption method of determining fluid saturation in core. Petrol. Trans. AIME 195, 322-323.

Ginsberg, T., Klein, J., Schwarz, E., Klages, J., 1982. Transient core debris bed heat removal experiments and analysis. In: International Meeting on Thermal Nuclear Reactor Safety, Chicago (USA).

Hall, P., Hall, C., 1981. Quenching of a hot particulate bed by bottom flooding: preliminary results and analysis. In: European Two-Phase Flow Group Meeting, Holland.

Hardee, H., Nilson, R., 1977. Natural convection in porous media with heat generation. Nucl. Sci. Eng. 63, 119-132.

Hassanizadeh, M., Gray, W.G., 1993. Toward an improved description of the physics of two-phase flow. Adv. Water Resour. 16, 53-67.

Hilfer, R., 1998. Macroscopic equations of motion for two-phase flow in porous media. Phys. Rev. E 58, 2090-2096.

Horne, R., Ramey, H., 1978. Steam/water relative permeabilities from production data. In: Geothermal Resources Council Annual Meeting, Hilo, HA (USA).

Hu, K., Theofanous, T., 1991. On the measurement and mechanism of dryout in volumetrically heated coarse particle beds. Int. J. Multiphase Flow 17, 519-532.

Jabbour, C., Quintard, M., Bertin, H., Robin, M., 1996. Oil recovery by steam injection: three-phase flow effects. J. Petrol. Sci. Eng. 16, 109-130.
Kalaydjian, F., 1987. A macroscopic description of multiphase flow in porous media involving spacetime evolution of fluid/fluid interface. Transp. Porous Media 2 $537-552$.

Kaviany, M., 1995. Principles of Heat Transfer in Porous Media, second ed. SpringerVerlag.

Lasseux, D., Ahmadi, A., Abbasian Arani, A.A., 2008. Two-phase inertial flow in homogeneous porous media: a theoretical derivation of a macroscopic model. Transp. Porous Media 75, 371-400.

Lichtenecker, K., 1926. P. Phys. Zeits, 27-115.

Lide, D., 1990. CRC Handbook of Chemistry and Physics, 70th Edn. CRC Press, Boca Raton, FL.

Lipinski, R., 1982. A model for cooling and dryout in particle beds. Technical Report SAND 82-0765, NUREG/CR-2646 Sandia National Labs.

Lipinski, R., 1984. A coolability model for post-accident nuclear reactor debris. Nucl. Technol. 65, 53-66.

Muskat, M., 1937. The Flow of Homogeneous Fluids Through Porous Media McGraw-Hill, New York.

Panfilov, M., Panfilova, I., 2005. Phenomenological meniscus model for two-phase flows in porous media. Transp. Porous Media 58, 87-119.

Quintard, M., Whitaker, S., 1990. Two-phase flow in heterogeneous porous media I: the influence of large spatial and temporal gradients. Transp. Porous Media 5, $341-379$.

Reed, A., 1982. The effect of channeling on the dryout of heated particulate beds immersed in a liquid pool (Ph.D. thesis). MIT Cambridge (USA).

Repetto, G., Chikhi, N., Fichot, F., 2013. Main outcomes on debris bed cooling from PRELUDE experiments. In: 6th European Review Meeting on Severe Accident Research (ERMSAR-2013), Avignon, France.

Saraf, D., Fatt, I., et al., 1967. Three-phase relative permeability measurement using a nuclear magnetic resonance technique for estimating fluid saturation. Soc. Petrol. Eng. J. 7, 235-242.

Schmidt, W., 2004. Influence of multidimensionality and interfacial friction on the coolability of fragmented corium. Technical Report ISSN-0173-6892 IKE Stuttgart University.

Schmidt, W., 2006. Interfacial drag of two-phase flow in porous media. Int. J. Multiphase Flow 33, 638-657.

Schulenberg, T., Müller, U., 1987. An improved model for two-phase flow through beds of coarse particles. Int. J. Multiphase Flow 13, 87-97.

Tung, V., Dhir, V., 1986. On fluidization of a particulate bed during quenching by flooding from the bottom. In: Proceedings of the 6th Information Exchange Meeting on Debris Bed coolability (pp. 14-1,14-13).

Tung, V., Dhir, V., 1988. A hydrodynamic model for two-phase flow through porous media. Int. J. Multiphase Flow 14, 47-65.

Tutu, N., Ginsberg, T., Chen, J., 1984a. Interfacial drag for two-phase flow through high permeability porous beds. J. Heat Transfer 106, 865-870.

Tutu, N., Ginsberg, T., Chen, J., 1984b. Interfacial drag for two-phase flow through high permeability porous beds. In: ASME (Ed.), Interfacial Transport Phenomena. Chen and Bankoff, New-York, USA.

Tutu, N., Ginsberg, T., Klein, J., Klages, J., Schwarz, C., 1984. Debris bed quenching under bottom flood conditions. Technical Report NUREG/CR-3850 Brookhaven National Labs.

Whitaker, S., 1986. Flow in porous media II: the governing equations for immiscible two-phase flow. Transp. Porous Media 1, 105-125.

Yano, T., 1984. Void fraction measurement by a gamma-ray densitometer under instantaneous pipe rupture. Nucl. Eng. Des. 79, 101-113.

Zakri, T., 1997. Contribution à l'étude des propriétés diélectriques de matériaux poreux en vue de l'estmation de leur teneur en eau: modèles de mélange et résultats expérimentaux (Ph.D. thesis). INPG.

Zakri, T., Laurent, J.-P., Vauclin, M., 1998. Theoretical evidence for Lichtenecker's mixture formulae based on the effective medium theory. Appl. Phys. 31, 15891594.

Zirnig, W., 1978. Beta absorption measuring system for steam-water-air mixture density in containment loca experiments. In: Transient two-phase flow, Proceedings of the second CSNI specialists meeting, Paris. 